\title{
Effects of grafting on key photosynthetic enzymes and gene expression in the citrus cultivar Huangguogan
}

\author{
L. Liao', S.Y. Cao', Y. Rong' and Z.H. Wang ${ }^{1,2}$ \\ ${ }^{1}$ College of Horticulture, Sichuan Agricultural University, Chengdu, Sichuan, China \\ ${ }^{2}$ Institute of Pomology and Olericulture, Sichuan Agricultural University, Chengdu, \\ Sichuan, China
}

Corresponding author: Z.H. Wang

E-mail: wangzhihui_siau@126.com

Genet. Mol. Res. 15 (1): gmr.15017690

Received September 22, 2015

Accepted December 4, 2015

Published March 4, 2016

DOI http://dx.doi.org/10.4238/gmr.15017690

\begin{abstract}
Grafting influences scion photosynthetic capacity and fruit quality. Ribulose-1,5-bisphosphate carboxylase/oxygenase (Rubisco), which strongly affects photosynthetic rate, and Rubisco activase (RCA), which regulates Rubisco activity, are two key photosynthetic enzymes. However, little information is available regarding the effect of grafting on the concentration and expression of Rubisco and RCA in the citrus cultivar Huangguogan. The objective of this study was to investigate the effect of grafting Huangguogan plants onto trifoliate orange, tangerine, and orange on: 1) the concentration of Rubisco and RCA; 2) the mRNA levels of $r b c L$, $r b c S$, and $r c a$; and 3) fruit quality. Overall, the results showed that when Huangguogan plants budded on tangerine and orange, they had better fruit quality, while on trifoliate orange they had higher Rubisco concentration. Tangerine and orange are probably the most suitable rootstocks for Huangguogan plants given the environmental conditions of Sichuan Province, China.
\end{abstract}

Key words: Gene cloning; Changing patterns; Standard cultivation; Total soluble solid; Seedless citrus hybrid 


\section{INTRODUCTION}

Huangguogan is a new late maturing, high-yield, and seedless citrus hybrid produced by crossing orange and tangerine. The main area of production in China is Sichuan Province, but it has been wide spread in many areas of the country since the $2010 \mathrm{~s}$. In spite of the increasing popularity of Huangguogan in the market, there is limited information regarding the effect of grafting on key photosynthetic enzymes and fruit quality.

Many studies have focused on the influence of citrus rootstocks on fruit quality (Georgiou, 2002; Forner-Giner et al., 2003; Bassal, 2009, Castle et al., 2010). However, the influence of rootstock on the photosynthetic capacity of scions may be a key factor when determining plant performance, in terms of vigor and fruit quality. Morinaga and Ikeda (1990) suggested that the leaf photosynthetic rate and product distribution differ among rootstocks, and scion behavior is probably influenced by rootstock-induced effects on leaf gas exchange (González-Mas et al., 2009; Rodríguez-Gamir et al., 2010). Graham and Syvertsen (1985) showed that the hydraulic conductivity of rootstock is positively correlated with the exchange rate of $\mathrm{CO}_{2}$ in citrus leaves. Carbon sequestration in terrestrial ecosystems is a result of the assimilation of $\mathrm{CO}_{2}$ by autotrophic bacteria, algae, and plants via the Calvin-Benson-Basham cycle (Tabita, 1999).

Rubisco is the most abundant protein on Earth (Raven, 2013). It is a key photosynthetic enzyme responsible for the incorporation of atmospheric $\mathrm{CO}_{2}$ into ribulose bisphosphate (RuBP), a process that generates the necessary building blocks for carbohydrate biosynthesis (Andersson and Backlund, 2008). However, Rubisco also has negative effects on crop yield (Ainsworth and Ort, 2010). Rubisco is composed of eight large subunits (RBCL) and eight small subunits (RBCS) (Ellis, 1979). In higher plants, RBCL is encoded by the chloroplastic rbcL gene, while RBCS is encoded by members of the nuclear rbcS gene family (Sasanuma, 2001; Wostrikoff and Stern, 2007). The expression of $r b c L$ and $r b c S$ is highly regulated and can be influenced by cell and tissue development (Patel et al., 2004; Majeran et al., 2005), photosynthetic metabolism (Acevedo-Hernández et al., 2005), nutrients, and plant regulators (Imai et al., 2005; Patel et al., 2006). Liu et al. (2013) suggested that the rootstocks affect the regulation of photosynthesis in cucumber leaves, since they affect the initial and total Rubisco activity by influencing gene expression. Rubisco activase (RCA) is also considered to be a key photosynthetic enzyme (Portis Jr., 2003). In higher plants, the active state of Rubisco is strictly dependent on the activity of RCA (Henderson et al., 2013).

The objective of this study was to investigate the effect of grafting Huangguogan plants onto trifoliate orange, tangerine, and orange on 1) the concentration of Rubisco and RCA; 2) the mRNA levels of $r b c L, r b c S$, and $r c a$; and 3) fruit quality.

\section{MATERIAL AND METHODS}

\section{Rootstocks and cultivation}

The rootstocks included trifoliate orange [Poncirus trifoliata (L.) Raf; PT], tangerine (Citrus reticulata Blanco; CR), and orange [Citrus junos (Sieb.) Tanaka; CJ]. Ungrafted plants, Huanggougan/Huanggougan (CK), and three combinations of grafted plants, Huanggougan/Trifoliate Orange (HG/PT), Huanggougan/Tangerine (HG/CR), and Huanggougan/Orange (HG/CJ), were used in this study. Seeds of trifoliate orange, tangerine, and orange were obtained from the Fruit Research Institute of Sichuan Agricultural University. All seeds were planted in April 2000. The seedlings were transplanted in the nursery of the Huangguogan Demonstration Garden in April 2001 and 
budded in March 2002. Buds were taken from virus-free Huangguogan trees, and all scions were obtained from the same clonal strain.

The trees were raised using standard cultural practices. Uniform 1-year-old budded trees were planted in March 2003 at the Huangguogan Demonstration Garden in a randomized complete block design with three-tree plots for each rootstock and three replications. Each plot was $5 \times 4 \mathrm{~m}$. The annual application of urea, calcium superphosphate, and potassium sulfate was 930-1125 kg/ ha, $1350-1500 \mathrm{~kg} / \mathrm{ha}$, and $\sim 540 \mathrm{~kg} / \mathrm{ha}$, respectively. Base fertilizer was applied once in October and then topdress fertilizer was applied three times: 1 month before flowering, once during the formation of young fruit, and once during fruit ripening. When young fruits began to grow, $\mathrm{N}$ and $\mathrm{P}$ were applied three times at concentrations of 30,20 , and 10 by weight. Trees were pruned and sprayed with insecticides, fungicides, and nutritional solutions as needed.

\section{Evaluation of fruit quality}

In total, 36 fruits were randomly collected from each replication. For each rootstock, fruits were harvested seven times at 20-day intervals during ripening. The total soluble solid (TSS) concentration was measured with a hand-held refractometer (Atago Co. Ltd., Japan). Titratable acidity (TA) (mEq NaOH $100 \mathrm{~g} /$ fresh fruit) was measured using $10 \mathrm{~mL}$ fruit juice diluted with distilled water (1:2) and titrated to $\mathrm{pH} 8.2$ using $0.1 \mathrm{~N} \mathrm{NaOH}$. The 2,6-dichloro-phenol-indophenol-titration method was used to determine the concentration of vitamin $\mathrm{C}$ and the Fehling reagent method was used to determine the concentration of total sugars.

\section{Measurement of enzyme concentrations}

A total of 36 leaf samples were collected from each replicate at 9:00 am and ground to a fine powder in liquid nitrogen. The concentrations of Rubisco and RCA enzymes were determined using Plant Rubisco ELISA Kit and Plant Rubisco Activase ELISA Kit (Shanghai BOYE Biology Science and Technology Co. Ltd., China) according to the manufacturer instructions.

\section{Total RNA extraction and gene expression analysis}

Total RNA was extracted from leaves using TRIzol (Toyobo, Osaka, Japan) according to the manufacturer instruction and then treated with RNase-free DNase to remove any contaminating DNA. First-strand cDNA produced from the total RNA was synthesized using M-MuLV reverse transcriptase and oligo-( $(\mathrm{dT})_{18}$ primers following the manufacturer instructions (Takara, Sichuan, China). Gene expression in each tissue was measured using real-time polymerase chain reaction (qRT-PCR). The primers (Table 1) were designed using the Primer express 3.0 software. Sequence data have been submitted to the GenBank database under the accession Nos. KP729049 (rca), KP729050 ( $r b c L)$, and KP729051 (rbcS). The actin gene (GenBank accession No. GQ389668.1) was used as an internal control. PCR was performed using LightCycler 480 SYBR Green I master kit (Roche Diagnostics, Mannheim, Germany) according to the manufacturer instructions. Amplification included a 5 -min preincubation step at $95^{\circ} \mathrm{C}$, followed by 40 cycles at $95^{\circ} \mathrm{C}$ for $10 \mathrm{~s}, 58^{\circ} \mathrm{C}$ for $15 \mathrm{~s}$, and $72^{\circ} \mathrm{C}$ for $20 \mathrm{~s}$. PCR products were quantified using the LightCycler 480 qRT-PCR detection system with SYBR Green I master kit (Roche Diagnostics). All reactions were run in triplicate. The specificity of PCR was determined by melting curve analysis, and data were analyzed using the $2^{-\Delta \Delta C t}$ method (Livak and Schmittgen, 2001). 
Table 1. Primers used for cloning and real-time polymerase chain reaction (qRT-PCR) assays.

\begin{tabular}{|c|c|c|c|}
\hline Gene & Primer pairs & Amplicon size (bp) & Application \\
\hline$R b c L-1 \mathrm{~F}$ & GAGCCCGTTGCTGGAGAA & \multirow[t]{2}{*}{590} & \multirow[t]{2}{*}{ Cloning } \\
\hline$R b c L-1 \mathrm{R}$ & CAATAATGAGCCAAGGTAG & & \\
\hline$R b c L-2 \mathrm{~F}$ & CCAAGGTAGTATTTGCGGTGAA & \multirow[t]{2}{*}{285} & \multirow[t]{2}{*}{ qRT-PCR } \\
\hline$R b c L-2 R$ & GTAGGGCGGTTTATGAATGTCT & & \\
\hline$R b c S-1 F$ & CTACGATGGACGCTACTGG & \multirow[t]{2}{*}{328} & \multirow[t]{2}{*}{ Cloning } \\
\hline$R b c S-1 R$ & AAGAGGGAAACGGGAAAA & & \\
\hline$R b c S-2 \mathrm{~F}$ & AGTTGGAGAAAGGATGGGTGTA & \multirow[t]{2}{*}{167} & \multirow[t]{2}{*}{ qRT-PCR } \\
\hline RbcS-2R & TCGGACGAATGAATGTGGGTAT & & \\
\hline$R c a-1 \mathrm{~F}$ & TCCGATGACCAACAAGAC & \multirow[t]{2}{*}{649} & \multirow[t]{2}{*}{ Cloning } \\
\hline$\overline{R c a-1 R}$ & GGATAAGAGGAGCATACAAG & & \\
\hline Rca-2F & CCAAGGTCTCCGCACATACAA & \multirow[t]{2}{*}{255} & \multirow[t]{2}{*}{ qRT-PCR } \\
\hline Rca-2R & TCTCCAGCATTGCCACTTTCC & & \\
\hline Actin-1F & CCATCAAGGCAGGGTTCA & \multirow[t]{2}{*}{414} & \multirow[t]{2}{*}{ Cloning } \\
\hline Actin-1R & ATAAGGGCGTCTGTAAGG & & \\
\hline Actin-2F & AGGCTCCACAAGCAAGTATTA & \multirow[t]{2}{*}{210} & \multirow[t]{2}{*}{ qRT-PCR } \\
\hline Actin-2R & CATCAAGGCAGGGTTCACATT & & \\
\hline
\end{tabular}

$\mathrm{F}$ indicates forward and $\mathrm{R}$ indicates reverse.

\section{Statistical analysis}

All experiments were performed in triplicate. Statistical analysis was performed using the SAS software (SAS Institute, Cary, NC, USA). Analysis of variance was applied to assess differences between the treatments. Data are reported as means \pm standard deviation (SD). Differences between means were established using the Duncan multiple range test $(P<0.05)$.

\section{RESULTS}

\section{Rubisco and RCA concentrations}

Grafting significantly affected RCA concentration (Figure 1). Following color change, there was very little variation in the concentration of RCA in grafting combinations during the first 40 days (Figure 1 ) and this then increased gradually reaching maximum values 80 days later. There were no significant differences in the mean RCA concentrations among HG/CR, HG/CJ, HG/PT, and CK plants, and their maximum values were $168.03,179.22,151.88$, and $142.88 \mathrm{ng} / \mathrm{L}$, respectively (Figure 1). Compared to CK, the concentration of RCA enzyme increased in the leaves of grafted plants, and this increase was more significant in the leaves of HG/CJ plants.

The pattern of Rubisco concentration fluctuated similarly in grafted plants and in CK plants. The concentration of Rubisco first increased and then decreased before and after fruit ripening, respectively (Figure 2), and was significantly higher in grafted plants than in CK plants. Rubisco reached maximum levels in HG/CJ and CK plants on February 15, and on March 5 in HG/PT and HG/CR plants (Figure 2). HG/CJ plants contained the highest concentration (104.91 ng/L) of Rubisco, which was significantly different compared to other grafting combinations before March, after which these differences were not significant (Figure 2). 


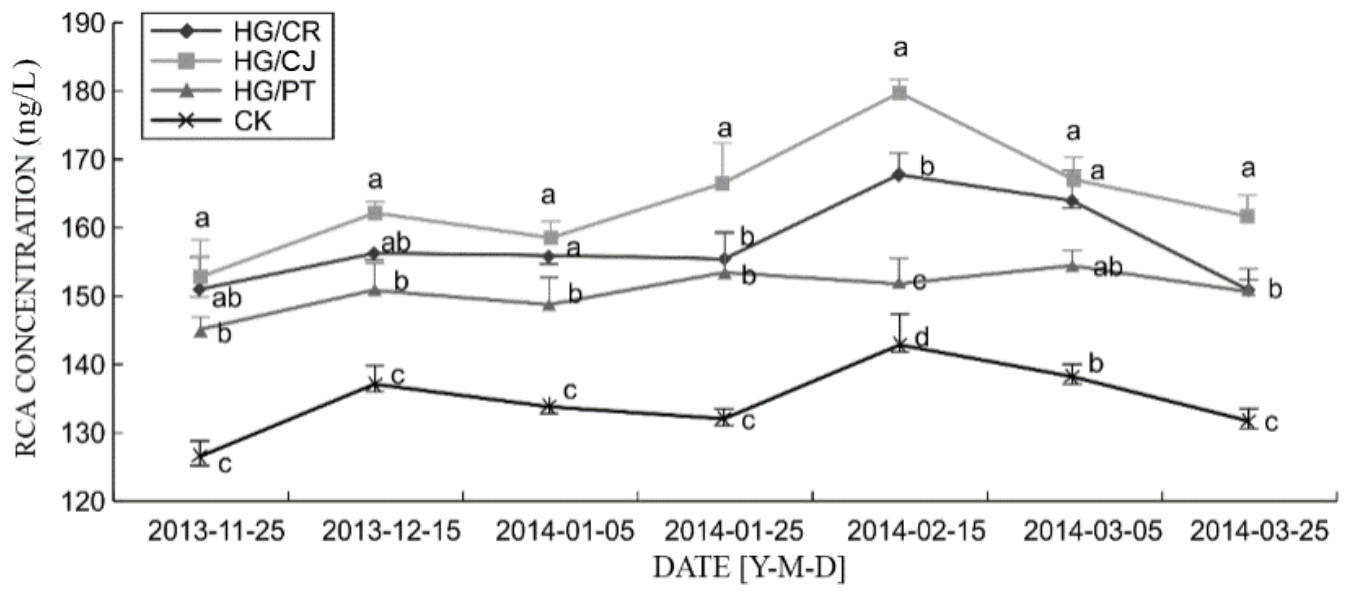

Figure 1. Changes in Rubisco activase (RCA) concentration during fruit ripening of Huangguogan grafted onto tangerine (HG/CR), orange (HG/CJ), trifoliate orange (HG/PT), and Huanggougan (CK). Bars represent means $\pm \mathrm{SD}$ $(\mathrm{N}=9)$. Different letters indicate significant differences $(P<0.05)$ according to the Duncan multiple range test.

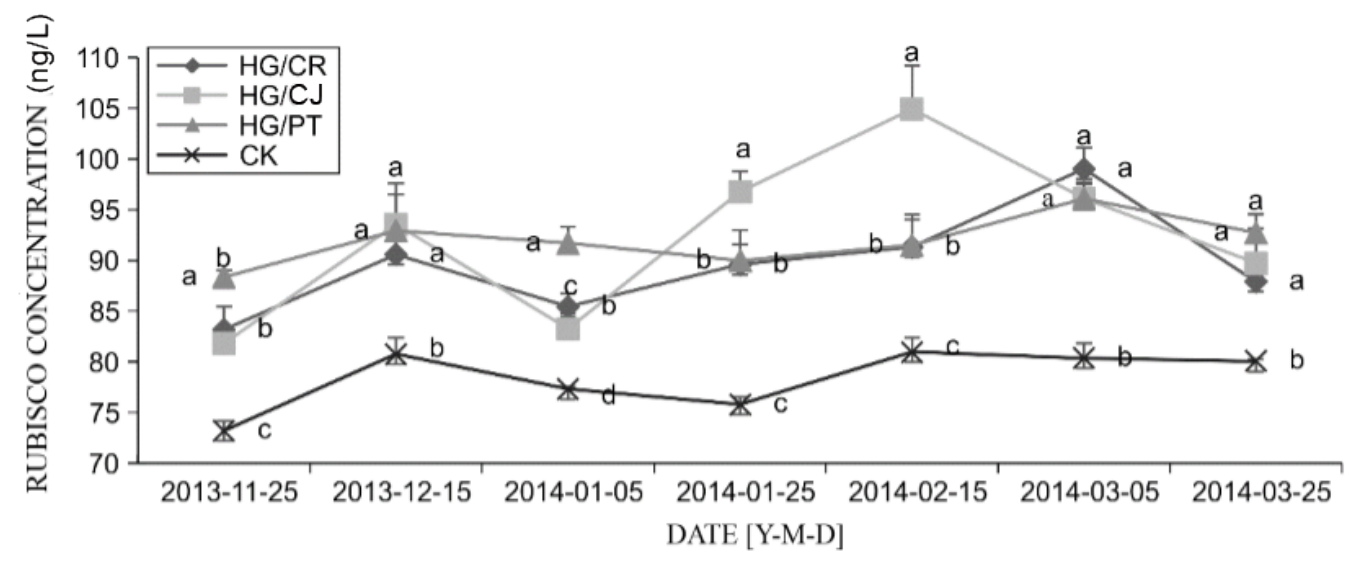

Figure 2. Changes in Rubisco carboxylation during fruit ripening of Huangguogan grafted onto tangerine (HG/CR), orange (HG/CJ), trifoliate orange (HG/PT), and Huanggougan (CK). Bars represent means $\pm S D(N=9)$. Different letters indicate significant differences $(P<0.05)$ according to the Duncan multiple range test.

\section{mRNA expression of the $r b c S, r b c L$, and $r c a$ genes}

To further understand how rootstocks regulate key photosynthetic enzyme concentrations, RT-qPCR was conducted to determine the mRNA expression of $r b c S, r b c L$, and $r c a$ genes in the leaves of Huangguogan. The relative expression of Rubisco at the transcriptional level was significantly affected by grafting (Figures 3 and 4). The results showed that the relative mRNA expression of $r b c S$ (Figure 3) and rbcL (Figure 4) first increased and then declined rapidly to about 1/5 or $1 / 3$ of the maximum value, respectively. In $\mathrm{HG} / \mathrm{PT}, \mathrm{HG} / \mathrm{CR}$, and $\mathrm{CK}$ plants, the maximum level of expression was observed on March 5, while in HG/CJ plants this occurred on February 15. The transcriptional levels of rbcS in HG/PT (Figure 3) and rbcL in HG/CR (Figure 4) were higher than 
those in $\mathrm{HG} / \mathrm{CJ}$ plants during fruit ripening. In addition, the relative expression of $r b c L$ and $r b c S$ mRNA in all grafting combinations was significantly higher than that in CK.

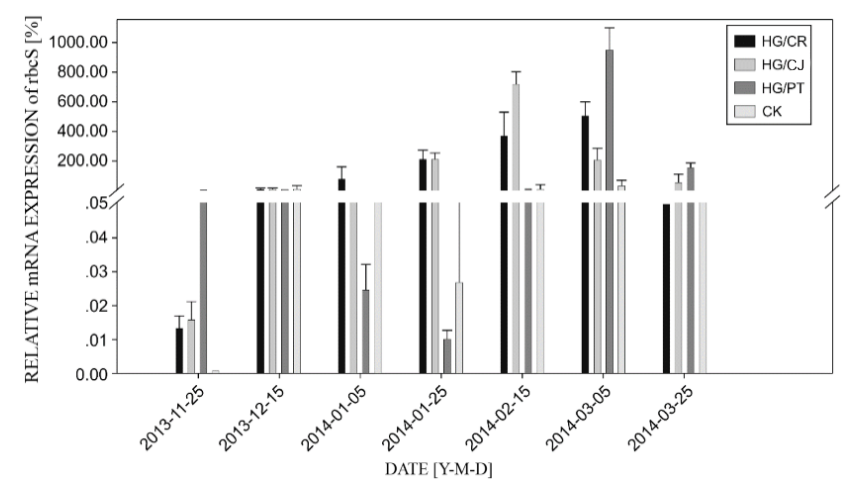

Figure 3. Effects of rootstocks on the relative mRNA expression of the rbcS gene in the leaves of Huangguogan grafted onto tangerine (HG/CR), orange (HG/CJ), trifoliate orange (HG/PT), and Huanggougan (CK). Bars represent means $\pm S D(N=9)$.

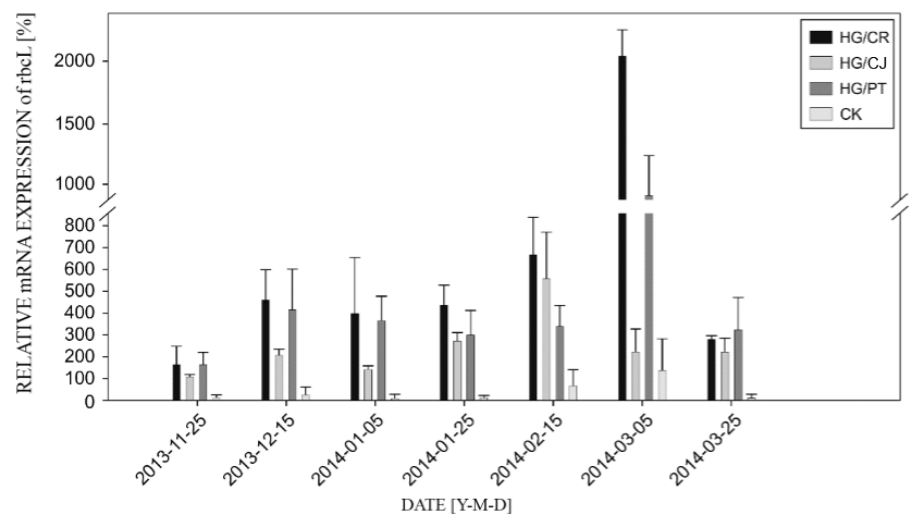

Figure 4. Effects of rootstocks on the relative mRNA expression of the $r b c L$ gene in the leaves of Huangguogan grafted onto tangerine (HG/CR), orange (HG/CJ), trifoliate orange (HG/PT), and Huanggougan (CK). Bars represent means $\pm \operatorname{SD}(N=9)$.

The level of $r c a$ transcription increased with fruit ripening, and was higher in all grafting combinations compared to CK (Figure 5). In particular, HG/CJ plants contained the expression of rca (Figure 5). The level of $r c a$ mRNA increased rapidly during fruit ripening and reached the maximum value on February 15 in HG/CJ and on March 5 in HG/PT, HG/CR, and CK plants. The level of $r c a$ mRNA declined quickly thereafter.

\section{Fruit quality}

Fruit quality was also influenced by grafting (Table 2). TSS was significantly higher in HG/PT, HG/CR, and HG/CJ compared with $\mathrm{CK}$, and HG/CR had the highest TSS concentration (13.32\%). Compared to CK, TSS in HG/PT, HG/CR, and HG/CJ was higher by 12.1, 19.7, and 
$6.4 \%$, respectively. CK produced fruits with the highest vitamin C content $(44.55 \mathrm{mg} / 100 \mathrm{~g})$, which was significantly different from that of HG/PT and HG/CR, but not of HG/CJ (Table 2). HG/CR and HG/PT produced fruits with the lowest vitamin $\mathrm{C}$ content. TA was higher in HG/PT and CK, but not significantly different than that in $\mathrm{HG} / \mathrm{CR}$ and $\mathrm{HG} / \mathrm{CJ}$ (Table 2). Compared to CK, TA of HG/CR and $\mathrm{HG} / \mathrm{CJ}$ was lower by 2.5 and $3.7 \%$, respectively. Compared to $\mathrm{CK}$, the total sugar content of HG/PT, $\mathrm{HG} / \mathrm{CR}$, and $\mathrm{HG} / \mathrm{CJ}$ was higher by $6.8,18.3$, and $10.2 \%$, respectively. $\mathrm{HG} / \mathrm{CR}$ contained the highest total sugars (10.41 g/100 mL), but did not differ significantly from those of HG/PT and HG/CJ.

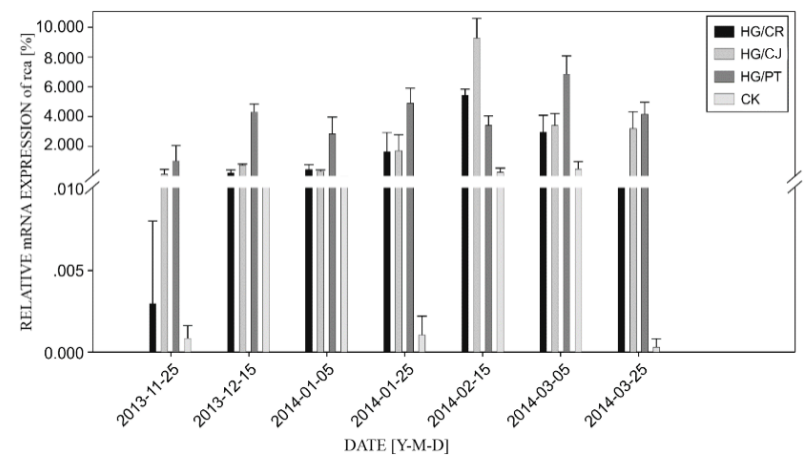

Figure 5. Effects of rootstocks on the relative mRNA expression of the rca gene in the leaves of Huangguogan grafted onto tangerine ( $\mathrm{HG} / \mathrm{CR})$, orange (HG/CJ), trifoliate orange (HG/PT), and Huanggougan (CK). Bars represent means $\pm \mathrm{SD}(\mathrm{N}=9)$.

Table 2. Fruit quality of Huangguogan grafted onto tangerine (HG/CR), orange (HG/CJ), trifoliate orange (HG/ $\mathrm{PT}$ ), and Huanggougan (CK).

\begin{tabular}{l|c|c|c|c}
\hline Rootstocks & Total soluble solids $(\%)$ & $\begin{array}{c}\text { Vitamin C } \\
(\mathrm{mg} / 100 \mathrm{~g})\end{array}$ & $\begin{array}{c}\text { Titratable acidity } \\
(\mathrm{g} / 100 \mathrm{~g})\end{array}$ & $\begin{array}{c}\text { Total sugars } \\
(\mathrm{g} / 100 \mathrm{~mL})\end{array}$ \\
\hline $\mathrm{HG} / \mathrm{CR}$ & $13.32 \pm 0.6^{\mathrm{a}}$ & $39.66 \pm 1.3^{\mathrm{a}}$ & $0.79 \pm 0.05^{\mathrm{a}}$ & $10.41 \pm 1.04^{\mathrm{a}}$ \\
\hline $\mathrm{HG} / \mathrm{CJ}$ & $11.83 \pm 0.25^{\mathrm{b}}$ & $44.16 \pm 2.85^{\mathrm{b}}$ & $0.78 \pm 0.02^{\mathrm{a}}$ & $9.7 \pm 1.25^{\mathrm{a}}$ \\
\hline $\mathrm{HG} / \mathrm{PT}$ & $12.47 \pm 1.5^{\mathrm{b}}$ & $38.72 \pm 2.05^{\mathrm{a}}$ & $0.81 \pm 0.07^{\mathrm{a}}$ & $9.4 \pm 1.2^{\mathrm{a}}$ \\
\hline $\mathrm{CK}$ & $11.12 \pm 0.08^{\mathrm{c}}$ & $44.55 \pm 3.55^{\mathrm{b}}$ & $0.81 \pm 0.03^{\mathrm{a}}$ & $8.8 \pm 0.7^{\mathrm{a}}$ \\
\hline
\end{tabular}

Different letters indicate significant differences $(\mathrm{P}<0.05)$ according to the Duncan multiple range test.

\section{DISCUSSION}

Several reports have established that rootstocks maintain their photosynthetic rates by alleviating oxidative damage, protecting chloroplast structure, and delaying photoinhibition (Zhen et al., 2011). Beakbane and Majumder (1975) also showed that rootstocks influence the density of stomata in scion leaves. In the present study, we observed that grafting enhanced the concentration of key photosynthetic enzymes in Huangguogan. The active levels of Rubisco and RCA in the grafted Huangguogan leaves were significantly higher than those in CK. Changes in Rubisco and RCA concentration were similar during fruit ripening, but the concentration of RCA was significantly higher than that of Rubisco, probably because RCA is a molecular chaperone that controls the switching of Rubisco conformation from inactive to active (Portis Jr., 1992, Ott et al., 2000; Spreitzer and Salvucci, 2002). The pattern of Rubisco expression changed during fruit ripening, probably because oxygenase plays the main role in this process, while after fruit ripening, carboxylase plays the primary role. The active level of Rubisco directly affects the photosynthetic rate 
(Morinaga and Ikeda, 1990), while several environmental factors have an indirect effect on the net photosynthetic rate (Brüggemann et al., 1992). The oxygenase activity of Rubisco results in the synthesis of phosphoglycolate, a molecule of limited use to most organisms. Phosphoglycolate is re-circulated by photorespiration, an energy-requiring salvage pathway, which causes a constant drain on the pool of RuBP and a decrease in the efficiency of carbon fixation by up to $50 \%$ (Andersson and Backlund, 2008). Suppression of Rubisco's oxygenation reaction has a positive effect on crop yield (Imai et al., 2005). Our study showed that CK had the lowest concentration of Rubisco, while HG/CR had the highest. These findings suggest that grafting might positively affect the yield performance and photosynthetic rate of Huangguogan.

RBCS is not essential for catalysis, because several configurations of RBCL retain some carboxylase activity and have unperturbed specificity (Andrews, 1988). However, considering that some Rubisco enzymes lack RBCS and have the lowest specificity values (Jordan and Ogren, 1981), we may assume that RBCS substantially contributes to the differences in kinetic properties observed among different Rubisco enzymes. On the other hand, hybrids containing foreign RBCS or enzymes with mutations in RBCS often display altered holo enzyme stability and/or specificity (Spreitzer and Salvucci 2002; Spreitzer, 2003). In the present study, we provide some evidence that grafting regulates the concentration of Rubisco by affecting gene expression. The changing patterns of $r b c S, r b c L$, and rca mRNA levels were similar in CK and under all grafting combinations. In addition, the changes in Rubisco and RCA concentrations were likely associated with the changes in the mRNA levels of $r b c L, r b c S$, and $r c a$. These results are consistent with those reported in rice leaves during ontogeny (Irving and Robinson, 2006). The consistent differences in the transcript levels and enzyme concentrations suggest that grafting plays an important role in the regulation of Rubisco synthesis. Thus, we conclude that grafting enhances the expression and concentration of Rubisco in Huangguogan leaves, and that different rootstocks have different effects on enzyme concentration and gene expression at different times.

Results from a previous study (Wutscher and Bistline, 1988) suggested that citrus rootstocks have well-established effects on fruit quality. Our results showed that grafting enhanced fruit quality, especially the total sugar content and TSS values, and that different rootstocks had different effects on these variables. Rootstock-induced changes in Huangguogan also improved the preservation time of fruit on the tree (data not shown). High expression levels of Rubisco and RCA in green organs made a substantial contribution to grain yield in wheat (Araus et al., 1993). Our study showed that HG/CJ plants had the highest levels of Rubisco and RCA expression, which is also suggestive of an increase in yield.

In conclusion, the results of this study showed that fruit quality, photosynthetic enzyme concentration, and gene expression of Huangguogan could be controlled by the proper selection of rootstock. Overall, the results showed that when Huangguogan plants budded on tangerine and orange, they had better fruit quality, while on trifoliate orange, they had a higher concentration of Rubisco. Tangerine and orange are probably the most suitable rootstocks for Huangguogan plants under the environmental conditions of Sichuan Province, China.

\section{Conflicts of interest}

The authors declare no conflict of interest.

\section{ACKNOWLEDGMENTS}

Research supported by the Science and Technology Support Project of Sichuan Province (\#2011NZ0034) and the Fund for Science and Technology of Sichuan Province (\#10ZC1454). 


\section{REFERENCES}

Acevedo-Hernández GJ, León P and Herrera-Estrella LR (2005). Sugar and ABA responsiveness of a minimal RBCS light-responsive unit is mediated by direct binding of ABI4. Plant J. 43: 506-519. http://dx.doi.org/10.1111/j.1365313X.2005.02468.x

Ainsworth EA and Ort DR (2010). How do we improve crop production in a warming world? Plant Physiol. 154: 526-530. http:// dx.doi.org/10.1104/pp.110.161349

Andersson I and Backlund A (2008). Structure and function of Rubisco. Plant Physiol. Biochem. 46: 275-291. http://dx.doi. org/10.1016/j.plaphy.2008.01.001

Andrews TJ (1988). Catalysis by cyanobacterial ribulose-bisphosphate carboxylase large subunits in the complete absence of small subunits. J. Biol. Chem. 263: 12213-12219.

Araus JL, Brown HR, Febrera A, Bort J, et al. (1993). Ear photosynthesis, carbon isotope discrimination and the contribution of respiratory $\mathrm{CO}_{2}$ to differences in grain mass in durum wheat. Plant Cell Environ. 16: 383-392. http://dx.doi. org/10.1111/j.1365-3040.1993.tb00884.x

Bassal M (2009). Growth, yield and fruit quality of 'Marisol' clementine grown on four rootstocks in Egypt. Sci. Hortic. (Amsterdam) 119: 132-137. http://dx.doi.org/10.1016/j.scienta.2008.07.020

Beakbane A and Majumder P (1975). A relationship between stomatal density and growth potential in apple rootstocks. J. Hortic. Sci. 50: 285-289.

Brüggemann W, van der Kooij TAW and van Hasselt PR (1992). Long-term chilling of young tomato plants under low light and subsequent recovery : II. Chlorophyll fluorescence, carbon metabolism and activity of ribulose-1,5-bisphosphate carboxylase/oxygenase. Planta 186: 179-187. http://dx.doi.org/10.1007/BF00196247

Castle WS, Baldwin JC and Muraro RP (2010). Performance of 'Valencia' sweet orange trees on 12 rootstocks at two locations and an economic interpretation as a basis for rootstock selection. Hortic. Sci. (Prague) 45: 523-533.

Ellis RJ (1979). The most abundant protein in the world. Trends Biochem. Sci. 4: 241-244. http://dx.doi.org/10.1016/0968$\underline{0004(79) 90212-3}$

Forner-Giner MA, Alcaide A, Primo-Millo E and Fomer JB (2003). Performance of 'Navelina' orange on 14 rootstocks in Northern Valencia. Sci. Hortic. (Amsterdam) 98: 223-232. http://dx.doi.org/10.1016/S0304-4238(02)00227-3

Georgiou A (2002). Evaluation of rootstocks for 'Clementine' mandarin in Cyprus. Sci. Hortic. (Amsterdam) 93: 29-38. http:// dx.doi.org/10.1016/S0304-4238(01)00311-9

González-Mas MC, Llosa MJ and Quijano A (2009). Rootstock effects on leaf photosynthesis in 'Navelina' trees grown in calcareous soil. Hortic. Sci. (Prague) 44: 280-283.

Graham J and Syvertsen J (1985). Host determinants of mycorrhizal dependency of citrus rootstock seedlings. New Phytol. 101: 667-676. http://dx.doi.org/10.1111/j.1469-8137.1985.tb02872.x

Henderson JN, Hazra S, Dunkle AM, Salvucci ME, et al. (2013). Biophysical characterization of higher plant Rubisco activase. Biochim. Biophys. Acta 1834: 87-97. http://dx.doi.org/10.1016/j.bbapap.2012.09.006

Imai K, Suzuki Y, Makino A and Mae T (2005). Effects of nitrogen nutrition on the relationships between the levels of rbcS and rbcL mRNAs and the amount of ribulose 1,5-bisphosphate carboxylase/oxygenase synthesized in the eighth leaves of rice from emergence through senescence. Plant Cell Environ. 28: 1589-1600. http://dx.doi.org/10.1111/j.13653040.2005.01438.x

Irving LJ and Robinson D (2006). A dynamic model of Rubisco turnover in cereal leaves. New Phytol. 169: 493-504. http:// dx.doi.org/10.1111/j.1469-8137.2005.01584.x

Jordan DB and Ogren WL (1981). Species variation in the specificity of ribulose biphosphate carboxylase/oxygenase. Nature 291: 513-515. http://dx.doi.org/10.1038/291513a0

Liu Z, Bie Z, Huang Y, Zhen A, et al. (2013). Rootstocks improve cucumber photosynthesis through nitrogen metabolism regulation under salt stress. Acta Physiol. Plant. 35: 2259-2267. http://dx.doi.org/10.1007/s11738-013-1262-5

Livak KJ and Schmittgen TD (2001). Analysis of relative gene expression data using real-time quantitative PCR and the $2^{(-D D}$ $\mathrm{C}(\mathrm{T}))$ Method. Methods 25: 402-408. http://dx.doi.org/10.1006/meth.2001.1262

Majeran W, Cai Y, Sun Q and van Wijk KJ (2005). Functional differentiation of bundle sheath and mesophyll maize chloroplasts determined by comparative proteomics. Plant Cell 17: 3111-3140. http://dx.doi.org/10.1105/tpc.105.035519

Morinaga K and Ikeda F (1990). The effects of several rootstocks on photosynthesis; distribution of photosynthetic product, and growth of young satsuma mandarin trees. J. Japan. Soc. Hort. Sci. 59: 29-34.

Ott CM, Smith BD, Portis AR Jr and Spreitzer RJ (2000). Activase region on chloroplast ribulose-1,5-bisphosphate carboxylase/ oxygenase. Nonconservative substitution in the large subunit alters species specificity of protein interaction. J. Biol. Chem. 275: 26241-26244. http://dx.doi.org/10.1074/jbc.M004580200

Patel M, Corey AC, Yin LP, Ali S, et al. (2004). Untranslated regions from C amaranth AhRbcS1 mRNAs confer translational enhancement and preferential bundle sheath cell expression in transgenic $\mathrm{C}_{4}$ Flaveria bidentis. Plant Physiol. 136: 3550 3561. http://dx.doi.org/10.1104/pp.104.051508 
Patel M, Siegel AJ and Berry JO (2006). Untranslated regions of FbRbcS1 mRNA mediate bundle sheath cell-specific gene expression in leaves of $\mathrm{a} \mathrm{C}_{4}$ plant. J. Biol. Chem. 281: 25485-25491. http://dx.doi.org/10.1074/jbc.M604162200

Portis AR Jr (1992). Regulation of ribulose 1, 5-bisphosphate carboxylase/oxygenase activity. Annu. Rev. Plant Biol. 43: 415437. http://dx.doi.org/10.1146/annurev.pp.43.060192.002215

Portis AR Jr (2003). Rubisco activase - Rubisco's catalytic chaperone. Photosynth. Res. 75: 11-27. http://dx.doi. org/10.1023/A:1022458108678

Raven JA (2013). Rubisco: still the most abundant protein of Earth? New Phytol. 198: 1-3. http://dx.doi.org/10.1111/nph.12197

Rodríguez-Gamir J, Intrigliolo DS, Primo-Millo E and Forner-Giner MA (2010). Relationships between xylem anatomy, root hydraulic conductivity, leaf/root ratio and transpiration in citrus trees on different rootstocks. Physiol. Plant. 139: 159-169. http://dx.doi.org/10.1111/j.1399-3054.2010.01351.x

Sasanuma T (2001). Characterization of the rbcS multigene family in wheat: subfamily classification, determination of chromosomal location and evolutionary analysis. Mol. Genet. Genomics 265: 161-171. http://dx.doi.org/10.1007/ $\underline{\text { s004380000404 }}$

Spreitzer RJ (2003). Role of the small subunit in ribulose-1,5-bisphosphate carboxylase/oxygenase. Arch. Biochem. Biophys. 414: 141-149. http://dx.doi.org/10.1016/S0003-9861(03)00171-1

Spreitzer RJ and Salvucci ME (2002). Rubisco: structure, regulatory interactions, and possibilities for a better enzyme. Annu. Rev. Plant Biol. 53: 449-475. http://dx.doi.org/10.1146/annurev.arplant.53.100301.135233

Tabita FR (1999). Microbial ribulose 1,5-bisphosphate carboxylase/oxygenase: a different perspective. Photosynth. Res. 60: 1-28. http://dx.doi.org/10.1023/A:1006211417981

Wostrikoff K and Stern D (2007). Rubisco large-subunit translation is autoregulated in response to its assembly state in tobacco chloroplasts. Proc. Natl. Acad. Sci. USA 104: 6466-6471. http://dx.doi.org/10.1073/pnas.0610586104

Wutscher $\mathrm{H}$ and Bistline $\mathrm{F}$ (1988). Performance of 'Hamlin' orange on 30 citrus rootstocks in southern Florida. J. Am. Soc. Hortic. Sci. 113: 493-497.

Zhen A, Bie Z, Huang Y, Liu Z, et al. (2011). Effects of salt-tolerant rootstock grafting on ultrastructure, photosynthetic capacity, and $\mathrm{H}_{2} \mathrm{O}_{2}$-scavenging system in chloroplasts of cucumber seedlings under $\mathrm{NaCl}$ stress. Acta Physiol. Plant. 33: 23112319. http://dx.doi.org/10.1007/s11738-011-0771-3 